\title{
Exploring the Impact of Traditional Communication Channels on Customer Purchase Decision: A Case Study of University Students in Ghana.
}

\author{
Isaac Ahakwa (D ${ }^{1}{ }^{1}$, Jingzhao Yang ${ }^{2}$, Evelyn Agba Tackie ${ }^{3}$, Kwame Bankole ${ }^{4}$ \\ School of Management, Jiangsu University, Zhenjiang-China ${ }^{1,2,3}$ \\ Vidmic Company Limited, Ghana ${ }^{4}$
}

\section{ABSTRACT}

Purpose- Marketers want to know the best advertisement medium which can make their advertising more effective. This study seeks to find a linkage between television advertisement, radio advertisement, newspaper advertisement, and outdoor advertisement towards customers' purchase decisions in Ghana.

Design/Methodology- Using University students in Ghana as a population, the study employed a simple random sampling approach and collected data from University students in UCC and KNUST. Seven hundred and fifty (750) responses were gathered from participants, but only seven hundred and thirty-two (732) responses were deemed suitable and were adopted to justify the proposed relationships. Data were analyzed using partial least squared built on Structural Equation Modeling (SEM)

Findings- The findings revealed that television advertisement has the greatest impact on customer purchase decision and was statistically significant at $\mathrm{p}<0.01$.

Practical Implications- This finding provides helpful suggestions for advertising professionals, market researchers, existing and emerging organizations to see television advertisements as an opportunity to increase awareness of goods and services as it tends to appeal to viewers' visual and sound senses, influencing customers' purchasing decisions and increasing sales of goods and services.

Corresponding author: isaacahakwa@gmail.com

\section{ARTICLE INFO}

Received: January 20, 2021

Revised: February 9 \& 11, 2021

Accepted: February 11, 2021

Published: February 12, 2021

\section{Keywords:}

Customer Purchase Decision

Television Advertisement

Radio Advertisement

Newspaper Advertisement

Outdoor Advertisement

$(\mathrm{cc}) \mathrm{BY}$ (C) 2021 The Author(s)

\section{Introduction}

One critical element contributing to organizations' survival and growth is their ability to make their consumers patronize the product or service they offer. However, the market is saturated with a countless number of products that are competing for existing and potential customers. Due to this reason, many organizations look for means through which they can attract, retain, and satisfy customers in the fastest possible 
manner. In addition to costs, efficiency, and delivery networks, firms can only boost their revenue and close relationships with consumers through promotional tools. In particular, to have a significant number of consumers aware of its products and services and provide a broad distribution of its goods and services, advertisement is the only successful medium open to businesses. It is a medium of contact that provides consumers with knowledge about products and services globally and helps them make purchase choices on a product or service. Advertising is the widely used system of communication between sellers and buyers. Richards and Curran (2002) see advertising as a paid intermediated way to communicate from a recognized source, intended to influence the one at the receiving end to make a decision immediately or later. (Heath et al., 2006) argued that there are three key reasons to advertise. The first reason is to draw the buyer's interest; second, to produce and expand brand identity and third, pursue the one receiving the advertisement. Mogaji, Czarnecka, and Danbury (2018) regarded advertisement as a mass marketing tool to bring customer knowledge, capture customers' interest, generate perception, and eventually affect their purchasing behavior and buying decisions as advertising can alter people's mindset and behaviors. Advertisers' primary purpose is to influence customers' purchasing behavior (Afzal \& Khan, 2015).

Marketers want to know the best advertisement medium which can make their advertising more effective (Mustafa \& Al-Abdallah, 2020). When engaging in an advertisement, corporations become even more mindful of choosing the medium and the type of advertising for goods (Mustafa \& Al-Abdallah, 2020). For years, traditional channels of communication have been used by organizations and have seen growth and progress over time. These outlets include outdoor advertisements, newspapers and magazines, television commercials, and radio advertisements (Mustafa \& Al-Abdallah, 2020). The possibility of accessing the networks mentioned above and their easy usage make traditional contact channels important (OviedoTrespalacios, Truelove, Watson, \& Hinton, 2019).

In Ghana, modern communication channels are difficult to compete with, making it more difficult for advertisers. Marketers in Ghana do not know the most efficient traditional communication medium to use (Zaglago, 2019). That is why they spend huge sums of money on all traditional communication platforms without having real scientific analysis on which network mostly influence customer purchasing decisions. Therefore, it is important to analyze the elements that influence the good or service's buying decision. Unfortunately, the literature on the relationship is of limited quality, particularly in the Ghanaian context, considering the significance and intensity of this issue. This research will provide advertising professionals, market researchers, existing and emerging indigenous organizations in Ghana with empirical evidence to identify and select the best-suited channels to market their products or services to their target customers. Therefore, this study aims to assess traditional communication channels' effect on consumer purchasing decisions, considering some selected elements of traditional communication networks such as television, radio, newspaper, and outdoor advertisement.

\section{Literature Review}

\section{Customer Purchase Decision}

Customer purchasing decisions are defined, according to (Singh et al., 2014), to mean how people want to invest their resources (time, money, effort) on consumer goods. Customer purchase decisions reflect on what, why, where, when, and how often they patronize, how they evaluate them after they purchase, and how they decide on future purchases. Consumers' purchasing decisions are selecting, purchasing, and utilizing goods and services to meet their needs. There are various mechanisms associated with the customer purchase decision. The customer attempts to figure out what goods he needs to buy for choosing only certain products that offer a higher value. The customer estimates the available money he will pay after selecting the goods. The customer analyzes the prevalent commodity prices and chooses which goods he will afford. This process is illustrated in figure 1. Businesses are set up to fulfill the client's demands and position the customer at the business core. 
Companies and advertisers must also anticipate customer buying preferences regarding their goods or services since they are increasingly introduced to new competitive goods by diverse marketing campaigns (Mahalaxmi \& Ranjith, 2016).

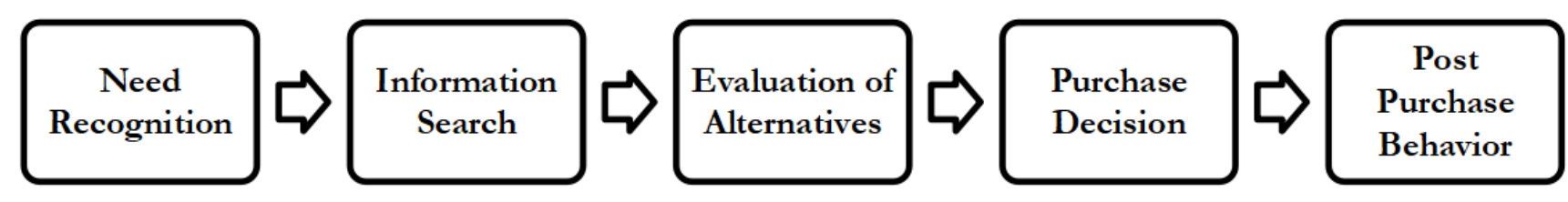

Figure 1: Customer Purchase Decision Process

\section{Television Advertisement}

Advertisers see television commercials as a significant component of the television industry and a key source of income, and television acts as an audience distribution system. (Shaikh, Hada, \& Shrestha, 2019). Television has been known as the glamour-advertising platform for many years (Mustafa \& Al-Abdallah, 2020). While the number of television viewers is declining, marketers who need to target mass audiences have found television the most favorable medium (Lee, Lee, \& Yang, 2017). Domazet, Đokić, and Milovanov (2017). The media managers try to identify the right balance among the viewers' side view of television shows and the target demographic, mainly because there is an already established viewers base for many television. Television has wide scope and exposure that surpasses other media; with its high-frequency volume, millions of viewers can easily be reached with just one advertisement, which comes at a low cost. Mustafa and Al-Abdallah (2020) claimed that television is seen as the most commonly used channel for advertising goods and services that cannot be promoted on radio or print media differently.

Compared to other traditional channels, consumers or viewers have high remembrance of advertised products through television channels and easily get persuaded. An analysis of consumer television viewing linked to real retail sales reveals that greater interaction with the display raises buyers' probability of recalling the commercial during the show (Tarik \& Adnan, 2018). As a contact medium, television is characterized by its segmentation capacity; it may target the exact display or the precise broadcasting network depending on the consumer's interests (Shafiq, Haque, Abdullah, \& Jan, 2017). Previous studies have linked television advertisements with customer purchase decisions (Anute, Deshmukh, \& Pawar; Majeed \& Razzak, 2011; Mustafa \& Al-Abdallah, 2020).

\section{H1: Television advertisements positively influence customers' purchase decisions.}

\section{Radio Advertisement}

Radio is considered an outstanding communication mode because it is less expensive to operate and easily gets a concentrated audience to listen amid its innovative versatility (Gijsenberg \& Nijs, 2019). According to Herget, Schramm, and Breves (2018), in shaping consumer perception of goods, radio commercials play a very important role. In contrast with other media advertisements, remembering a brand name and recollecting a thirty-second promotional note is very strong. Wide groups of corporations prefer radio as a promotional medium to meet narrowly defined aims (Modikeng, 2018). Russo, Valesi, Gallo, Laureanti, and Zito (2020) found out that radio as a contact medium has a dual benefit, thus, wide reach and cost-effectiveness. For radio, advertisers may reach different demographics on the premise that each network has a unique audience and industry (Mustafa \& Al-Abdallah, 2020). Mornings and afternoons are the most common hours for listening to the radio because people will often be in public or private vehicles commuting to and from their work. Within those hours, they are less engaged with work and will listen to the radio (Saleh, 2017). Radio advertisements generate customer excitement that raises purchases in retailers' stores (Wielhouwer, 2020). Radio advertising 
for store promotions can help the listener learn, make purchasing choices, or even go to the shops with their influenced peers to help them decide on picking items (Mustafa \& Al-Abdallah, 2020). Lankford (2018) observed that radio advertisements cover more sale information and therefore, the level of consumers' purchasing decision may increase based on competitive dynamics and organizational fitness displayed in the advertisement. There are various levels of emotions that can be activated by various radio advertisements, such as warmth, passion, pleasure, and desire. With the limited radio advertisements, motivational pleas for programs, experiential and utilitarian goods are more favored (Mustafa \& Al-Abdallah, 2020). Sight and mentality may also be affected by radio commercials, which in turn influences customer behavior. The effect on the perception of the customer helps to create consumer behavior with regard to the message disseminated (Mehdi, Paris, \& Balasubramanian, 2019). Previous studies have linked radio advertisement with customer purchase decisions and found a significant relationship between the two variables (Ayimey, Awunyo-Vitor, \& Gadawusu, 2013; Efstathiou, 2020; Mustafa \& Al-Abdallah, 2020; SRIVASTAVA, 2017).

\section{H2: Radio advertisements positively impact customers' purchase decisions.}

\section{Newspaper Advertisement}

Newspapers are one of the most common channels of communication and have been in existence for decades. Advertisers' goal is to influence product creation, sales practices, and customer purchasing choices through newspaper advertisements (Tamilselvan \& Kumaresan). Mogaji et al. (2018) reported that print media performs a significant role in the growth of other media, with newspapers being the most significant in this industry. Newspaper advertisements hold the greatest volume of information, according to Tao (2020), and are perceived as highly informative compared with other media, including television. Mustafa and Al-Abdallah (2020) have suggested that newspapers' facets help advertisers conveniently display their advertising in the favorite target newspaper with more data, facts, and photographs. Newspaper is very beneficial to the upscale audience. It is also circulated daily (or periodically) on a mass scale with opinion makers, especially adults, to target large demographic sections and offer them the news, entertainment, and advertisement (Saleh, 2017). Malthouse and Calder (2018) argued a link between how individuals respond to a given newspaper and how they respond to advertisements in that newspaper. Previous experiments have correlated newspaper advertisements with consumer purchase decisions and find a substantial association between the two variables. (Ingavale, 2013; Mustafa \& Al-Abdallah, 2020).

\section{H3: Newspaper advertisements positively influence customers' purchase decisions.}

\section{Outdoor Advertisement}

Outdoor advertising patterns are becoming more popular, and the use of these channels is regularly growing (Idris, Suhana, Ahmad, \& Wong, 2020). Since consumers are involved in multiple tasks during the day, marketers often find it difficult to locate them in particular places or within certain periods, so marketers introduced the billboards that carry messages of advertisement to the target market (Pourhossein \& Mahmoudabadi). Outdoor advertisement helps reach the local masses easily, and it is also bring in high levels of exposure, concrete evidence, and effectiveness so that most organizations have adopted its usage (Alalwan, 2018). Outdoor advertisements capture consumers' attention by creating an unforgettable impression (Shafiq et al., 2017). Business Wire (2002) believed that outdoor advertisement is the best medium of commercializing because viewers cannot delete or roll it over if they come across it. Outdoor advertisement tends to dominate the marketing field; with billboards, viewers see numerous advertisements without understanding them (Page, Anesbury, Moshakis, \& Grasby, 2018). Many studies have suggested some benefits of utilizing outdoor advertisement. The associated advantages are that it is positioned outdoor, so there is a tendency of getting thousands of audience (especially those nearer to the point of sale), it is geographically mobile, has a higher scope, economically, it is effective, has a higher rate of exposure, and the brand can easily be recognized. Mustafa and Al-Abdallah (2020) considered that billboards significantly draw consumers' minds to the 
advertised product/service. Outdoor is a twenty-four hours everyday advertisement, with an appropriate size and simple message, a fantastic visual effect. Outdoors lure current and future clients, who will boost the company's revenue (Page et al., 2018). Previous studies have linked outdoor advertisement with customer purchase decisions (Demiri \& Zekiri; Mustafa \& Al-Abdallah, 2020; Okanazu \& Madu, 2020; Sah, 2020; Warraich \& Ali, 2020).

H4: Outdoor advertisements positively influence customers' purchase decisions.

\section{The Conceptual Framework}

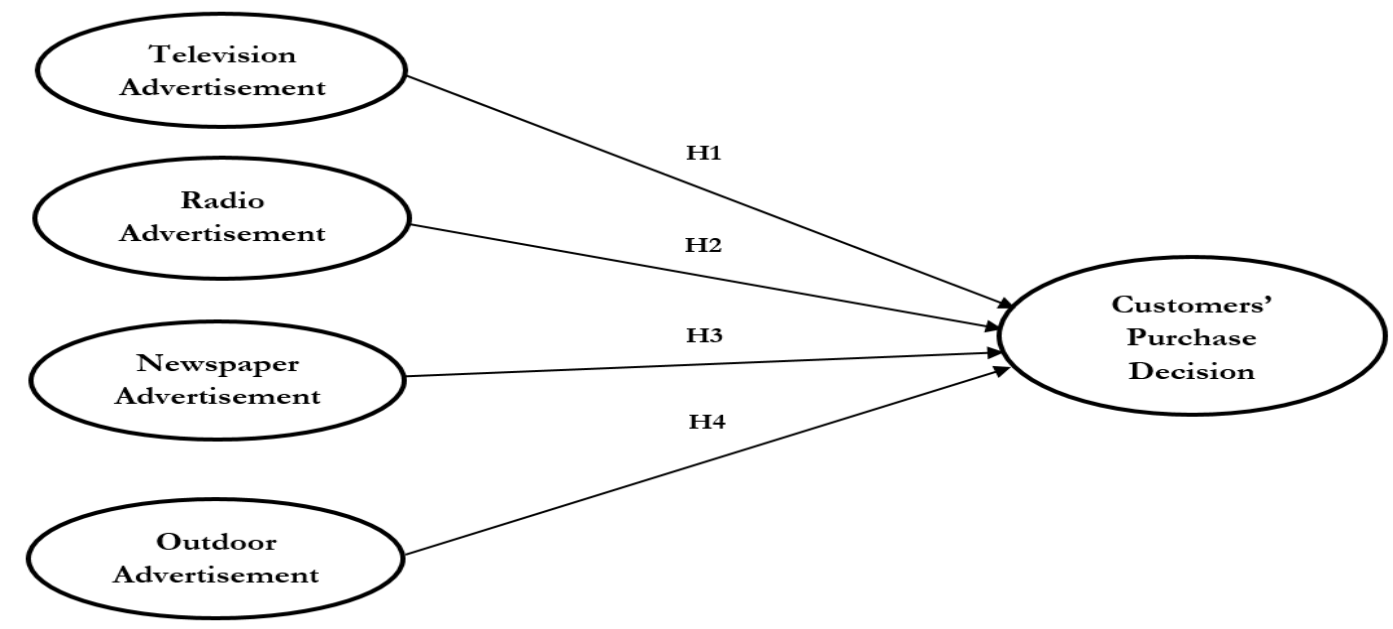

Figure 2: The Conceptual Framework

\section{Methodology}

\section{Research Design}

A research design is a collection of procedures and techniques used to capture and analyze the measurements of factors recognized in a research problem (Halldorsson, Castelijn, \& Creswell, 2019). To evaluate classification features, quantify numbers, and construct a predictive pattern to test hypotheses and explain results, the research used quantitative approaches. University students in Ghana are the population for this research, precisely students at the University of Cape Coast (UCC) and Kwame Nkrumah University of Science and Technology (KNUST). This research followed a simple random sampling technique where every person was given an equal opportunity to answer the questions asked. The sample size used for the analysis is seven hundred and fifty (750) in the two chosen universities, all of whom were university students.

\section{Data Instrument and Collection}

To reach the purpose of the study, the data were gathered from the study population. The research used the questionnaire as a medium to request information from the population. The questionnaire included questions related to the participants' demographic characteristics. There were questions in the second part of the questionnaire that helped examine the variables to be evaluated. Table 1 presents the number of items measured in the study as well as their sources. Participants were called upon to rate the questions based on the 5-point Likert with the scaling pole extending from strongly disagree (1) to strongly agree (5). Seven hundred fifty (750) online questionnaires were sent to respondents through various digital platforms. Seven hundred thirty-two (732) were deemed fit and accurate, then used for discussion. 
Table 1: Measurement of Variables

\begin{tabular}{lcc}
\hline Constructs & Number of Items & Literature Source \\
\hline Customer Purchase Decision & 8 & (Costa, 2014; Ingavale, 2013) \\
Television Advertisement & 3 & (Osewe, 2013) \\
Radio Advertisement & 3 & (Danaher \& Rossiter, 2011) \\
Newspaper Advertisement & 3 & (Anu \& Aswathy, 2014) \\
Outdoor Advertisement & 3 & (Kumar \& Raju, 2013) \\
\hline
\end{tabular}

\section{Data Analysis and Results}

Data was moved from the online survey questionnaire portal to the Microsoft Excel format for easy access and transition to the various research tools. The research involved exploratory and confirmatory studies in confirming the validity of the model. SPSS version 26.0 was used to process descriptive statistics to ascertain the demographic information of all respondents. Partial Least Squares (PLS) analysis using SmartPLS 3.0 software was used to assess the research model. The measurement model was tested for validity and reliability of the constructs. The structural model was then analyzed in conjunction with the procedures suggested for SEM (Hair Jr, Hult, Ringle, \& Sarstedt, 2016). A bootstrapping method (5000 resamples) was used to test the path coefficients' significance and loadings (Hair Jr et al., 2016). We also assessed the prediction error degree using PLSpredict as suggested by (Shmueli et al., 2019).

\section{Demographic Profile}

Table 2: Respondents Profile

\begin{tabular}{lcc}
\hline Demographic Characteristics & & $\mathbf{\%}$ \\
\hline Gender & Male & 32.3 \\
& Female & 67.7 \\
Age & $18-25$ years & 50.8 \\
& $26-30$ years & 21.2 \\
& $31-35$ years & 17.9 \\
Educational Level & 36 years and above & 10.1 \\
& Undergraduate & 61.5 \\
& Masters & 25.9 \\
Marital Status & Ph.D. & 5.5 \\
& Others & 7.1 \\
& Single & 72.8 \\
\hline
\end{tabular}

Respondents' descriptive statistics revealed that $32.3 \%$ of the overall response are males, while females accounted for $67.7 \%$. This finding reveals more females are admitted to University than males in the study area. The findings also revealed that $50.8 \%$ of those respondents were 18 to 25 years of age, $21.2 \%$ were 26 to 30 years of age, and $17.9 \%$ were 31 to 35 years of age, while $10.1 \%$ were 36 years of age older. The demographic findings also showed that $61.5 \%$ were undergraduate students, $25.9 \%$ were master's students, $5.5 \%$ were doctoral students (Ph.D.), and 7.1\% represented other students. Finally, Table 2 indicates that $72.8 \%$ of respondents were single, $20.5 \%$ were married, and $6.7 \%$ had divorced. 


\section{Assessment of the Measurement Model}

Table 3: Construct Reliability and Validity

\begin{tabular}{|c|c|c|c|c|c|}
\hline Construct & Notations & Loadings & $\begin{array}{l}\text { Cronbach } \\
\text { Alpha }(\alpha)\end{array}$ & $\begin{array}{c}\text { Composite } \\
\text { Reliability (CR) }\end{array}$ & AVE \\
\hline & CPD1 & 0.823 & \multirow{8}{*}{0.962} & \multirow{8}{*}{0.968} & \multirow{8}{*}{0.794} \\
\hline & CPD2 & 0.892 & & & \\
\hline & CPD3 & 0.910 & & & \\
\hline Customer Purchase & CPD4 & 0.951 & & & \\
\hline \multirow[t]{4}{*}{ Decision } & CPD5 & 0.947 & & & \\
\hline & CPD6 & 0.747 & & & \\
\hline & CPD7 & 0.948 & & & \\
\hline & CPD8 & 0.889 & & & \\
\hline \multirow{3}{*}{$\begin{array}{l}\text { Television } \\
\text { Advertisement }\end{array}$} & TAM1 & 0.808 & \multirow{3}{*}{0.810} & \multirow{3}{*}{0.888} & \multirow{3}{*}{0.725} \\
\hline & TAM2 & 0.843 & & & \\
\hline & TAM3 & 0.901 & & & \\
\hline \multirow{3}{*}{$\begin{array}{l}\text { Radio } \\
\text { Advertisement }\end{array}$} & RAM1 & 0.874 & \multirow{3}{*}{0.805} & \multirow{3}{*}{0.878} & \multirow{3}{*}{0.708} \\
\hline & RAM2 & 0.843 & & & \\
\hline & RAM3 & 0.914 & & & \\
\hline \multirow{3}{*}{$\begin{array}{l}\text { Newspaper } \\
\text { Advertisement }\end{array}$} & NAM1 & 0.868 & \multirow{3}{*}{0.709} & \multirow{3}{*}{0.835} & \multirow{3}{*}{0.630} \\
\hline & NAM2 & 0.718 & & & \\
\hline & NAM3 & 0.788 & & & \\
\hline \multirow{3}{*}{$\begin{array}{l}\text { Outdoor } \\
\text { Advertisement }\end{array}$} & OAM1 & 0.884 & \multirow{3}{*}{0.807} & \multirow{3}{*}{0.886} & \multirow{3}{*}{0.721} \\
\hline & OAM2 & 0.877 & & & \\
\hline & OAM3 & 0.784 & & & \\
\hline
\end{tabular}

Note: CPD, (Customer Purchase Decision); TAM, (Television Advertisement); RAM, (Radio Advertisement); NAM, (Newspaper Advertisement); OAM, (Outdoor Advertisement).

Table 3 displays the values of Factor Loading, Cronbach Alpha, Composite Reliability (CR), and Average Variance Extracted (AVE) after confirmatory factor analysis for all latent constructs. All the item loadings were above the threshold of 0.6 (Chin, Peterson, \& Brown, 2008). The Cronbach alpha, which measures the items' internal consistency, surpassed the recommended figure of 0.70 (Hair Jr et al., 2016). Composite reliability values in Table 3 surpassed the threshold value of 0.7 , while AVE surpassed the suggested value of 0.5 (Hair Jr et al., 2016). Therefore, the model is good enough for analysis since all the constructs have attained convergent validity, internal reliability, and construct reliability.

Table 4: Collinearity Value Assessed by VIF

\begin{tabular}{ll}
\hline Items & VIF \\
\hline CPD1 & 2.257 \\
CPD2 & 1.996 \\
CPD3 & 2.369 \\
CPD4 & 2.897 \\
CPD5 & 1.569 \\
CPD6 & 2.489 \\
CPD7 & 2.145 \\
CPD8 & 1.254 \\
TAM1 & 1.569 \\
\hline
\end{tabular}




$\begin{array}{ll}\text { TAM2 } & 1.920 \\ \text { TAM3 } & 2.297 \\ \text { RAM1 } & 2.076 \\ \text { RAM2 } & 1.570 \\ \text { RAM3 } & 1.829 \\ \text { NAM1 } & 1.547 \\ \text { NAM2 } & 1.360 \\ \text { NAM3 } & 1.347 \\ \text { OAM1 } & 1.941 \\ \text { OAM2 } & 1.935 \\ \text { OAM3 } & 1.555\end{array}$

Note: VIF (variance inflation factor); CPD, (Customer Purchase Decision); TAM, (Television Advertisement); RAM, (Radio Advertisement); NAM, (Newspaper Advertisement); OAM, (Outdoor Advertisement).

We then examine the model for collinearity issues using variance inflation factor (VIF). Table 4 shows the collinearity values of the various constructs assessed using VIF. Table 4 shows VIF values of the individual constructs being lesser than the limit value five (5) suggested by Kim (2019). This result signifies that the model has no collinearity problem (Ahakwa, Yang, Tackie, Odai, \& Dartey, 2021).

Table 5: Fornell-Larcker's Discriminant V alidity

\begin{tabular}{lccccc}
\hline Constructs & $\mathbf{1}$ & $\mathbf{2}$ & $\mathbf{3}$ & $\mathbf{4}$ & $\mathbf{5}$ \\
\hline Customer Purchase Decision & $\mathbf{0 . 8 9 1}$ & & & & \\
Newspaper Advertisement & 0.503 & $\mathbf{0 . 7 9 4}$ & & & \\
Outdoor Advertisement & 0.560 & 0.547 & $\mathbf{0 . 8 4 9}$ & & \\
Radio Advertisement & 0.388 & 0.351 & 0.400 & $\mathbf{0 . 8 4 1}$ & \\
Television Advertisement & 0.688 & 0.540 & 0.572 & 0.372 & $\mathbf{0 . 8 5 2}$ \\
\hline
\end{tabular}

To evaluate the discriminant validity (DV) of the model, Fornell-Larcker's Criterion is first used. The DV test measures the degree to which each variable does not replicate itself in the model's analysis. Table 5 reveals that the individual construct's AVE square root (diagonal values) is higher than its related correlation coefficients, suggesting sufficient DV (Fornell \& Larcker, 1981).

Table 6: Heterotrait-Monotrait Ratio (HTMT) for Discriminant V alidity (DV)

\begin{tabular}{lccccc}
\hline Constructs & $\mathbf{1}$ & $\mathbf{2}$ & $\mathbf{3}$ & $\mathbf{4}$ & $\mathbf{5}$ \\
\hline Customer Purchase Decision & & & & & \\
Newspaper Advertisement & 0.588 & & & & \\
Outdoor Advertisement & 0.626 & 0.719 & & & \\
Radio Advertisement & 0.405 & 0.427 & 0.465 & & \\
Television Advertisement & 0.773 & 0.684 & 0.695 & 0.395 \\
\hline
\end{tabular}

Some current disapprovals of the Fornell and Larcker (1981) criteria indicates that they do not effectively identify an absence of DV (Henseler, Ringle, \& Sarstedt, 2015). Henseler et al. (2015) advocated a different approach to measure the DV of the heterotrait-monotrait (HTMT) ratio of correlation based on the multi-trait-multimethod matrix. This new method was used to assess the DV, and the findings are presented in Table 6. When the HTMT value is larger than the threshold value of 0.85 (Kline, 2011) for the first criterion, then DV problem has occurred. However, as presented in Table 6, all the values were below the HTMT value of 0.85 . 


\section{Assessment of the Structural Mode}

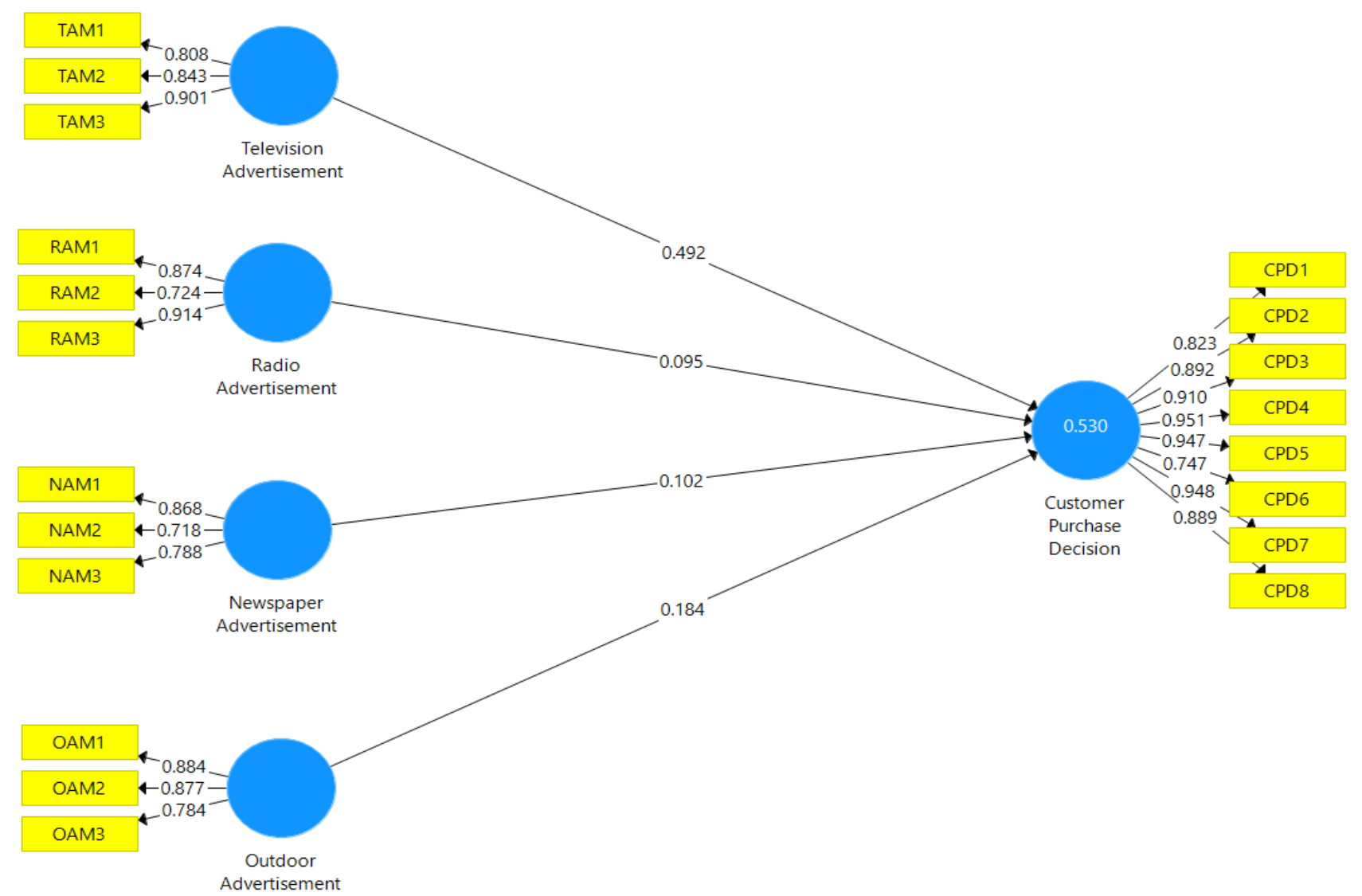

Figure 3: The Structural Model

Table 7: Hypotheses testing

\begin{tabular}{lcccc}
\hline Hypotheses & Path Coefficient $(\boldsymbol{\beta})$ & t-statistics & p-value & Decision \\
\hline H1: TAM $>>$ CPD & 0.492 & 13.822 & 0.000 & Supported \\
H2: RAM $>>$ CPD & 0.095 & 3.283 & 0.001 & Supported \\
H3: NAM $>$ CPD & 0.102 & 2.750 & 0.006 & Supported \\
H4: OAM $>$ CPD & 0.184 & 4.534 & 0.000 & Supported \\
\hline
\end{tabular}

Note: Critical t-statistics, *1.96 (P < 0.01); CPD, (Customer Purchase Decision); TAM, (Television Advertisement); RAM, (Radio Advertisement); NAM, (Newspaper Advertisement); OAM, (Outdoor Advertisement).

To test for the hypothesis of the study, the links between the variables used are established. Television advertisement positively influenced customer purchase decision $(\beta=0.492$, $t$-statistics $=13.822, \mathrm{p}<0.01)$, and radio advertisement positively influenced customer purchase decision $(\beta=0.095$, t-statistics $=3.283$, $\mathrm{p}<0.01)$. Newspaper advertisement positively influenced customer purchase decision $(\beta=0.102, t$-statistics $=2.750, \mathrm{p}<$ 0.01). Also, outdoor advertisement positively influenced customer purchase decision $(\beta=0.184$, t-statistics $=$ 4.534, $\mathrm{p}<0.01$ ). Consequently, all the hypotheses were supported (See Table 7). Furthermore, television advertisement, radio advertisement, newspaper advertisement, and outdoor advertisement explain 53.0\% of the total amount of variance in customer purchase decision; thus, $R^{2}=0.530$ (See Table 9), which is more than the value of 0.26 proposed by Cohen (1988), and this indicates that the model is substantial. 
Table 8: Effects Size

\begin{tabular}{lcc}
\hline Relationships & f square $\left.\boldsymbol{( f}^{\mathbf{}}\right)$ & Effect Size \\
\hline H1: TAM $>$ CPD & 0.303 & Strong \\
H2: RAM $>>$ CPD & 0.015 & Small \\
H3: NAM $>$ CPD & 0.014 & Small \\
H4: OAM $>>$ CPD & 0.041 & Medium \\
\hline
\end{tabular}

Note: CPD, (Customer Purchase Decision); TAM, (Television Advertisement); RAM, (Radio Advertisement); NAM, (Newspaper Advertisement); OAM, (Outdoor Advertisement).

Next, we assessed the effect sizes $\left(f^{2}\right)$ employing Cohen's (1988) threshold values of 0.02, 0.15, and 0.35 for small, medium, and large effects, respectively. Table 8 reveals that television advertisement has a significant strong effect on customer purchase decision with an $f^{2}$ value of 0.303 , followed by outdoor advertisement with significant medium effects on customer purchase decision with an $f^{2}$ value of 0.041 . Also, both newspaper advertisement and radio advertisement had a significant small effect on customer purchase decisions with an $\mathrm{f}^{2}$ value of 0.014 and 0.015 , respectively.

Table 9: Predictive Relevance

\begin{tabular}{lccc}
\hline Construct & R square $\left(\boldsymbol{R}^{\mathbf{2}}\right)$ & Adjusted $\boldsymbol{R}^{\mathbf{2}}$ & Q square $\left(\boldsymbol{Q}^{\mathbf{2}}\right)$ \\
\hline Customer Purchase Decision & 0.530 & 0.528 & 0.388 \\
\hline
\end{tabular}

The predictive sample reuse technique $\left(Q^{2}\right)$, in addition to the size effect of the $R^{2}$ and $f^{2}$, can effectively demonstrate the relevancy of the model (Chin et al., 2008). The study acquired its $Q^{2}$ through cross-validated redundancy techniques. A $Q^{2}$ value bigger than zero $(0)$ shows that the model has predictive relevance; however, a $Q^{2}$ value below 0 means the model's predictive relevance lacks. Therefore, our $Q^{2}$ value of 0.388 in table 9 suggested that the model had acceptable predictive relevance.

Table 10: PLS Assessment of Manifest Variable (Original Model)

\begin{tabular}{lccccc}
\hline PLS & RMSE & $\boldsymbol{Q}^{\mathbf{2}}$ predict & LM & RMSE & (PLS RMSE)-(LM RMSE) \\
\hline CPD1 & 0.661 & 0.459 & CPD1 & 0.691 & -0.030 \\
CPD2 & 0.384 & 0.480 & CPD2 & 0.388 & -0.004 \\
CPD3 & 0.514 & 0.426 & CPD3 & 0.519 & -0.005 \\
CPD4 & 0.396 & 0.427 & CPD4 & 0.398 & -0.002 \\
CPD5 & 0.397 & 0.433 & CPD5 & 0.399 & -0.002 \\
CPD6 & 0.456 & 0.196 & CPD6 & 0.469 & -0.013 \\
CPD7 & 0.462 & 0.447 & CPD7 & 0.466 & -0.004 \\
CPD8 & 0.510 & 0.402 & CPD8 & 0.511 & -0.001 \\
\hline
\end{tabular}

*RMSE: Root Mean Squared Error; *LM: Linear Regression Model; CPD, (Customer Purchase Decision).

Following the recommended guideline in assessing the prediction error degree (Shmueli et al., 2019), evaluation of the PLS-SEM $Q^{2}$ predict values for all the indicators of the measurement model was done. Table 10 reveals that all the $Q^{2}$ predict values are greater than zero $(0)$, indicating a highly symmetrical distribution of prediction errors. We then compared the naive LM benchmark (Table 10) with the RMSE values of the PLSSEM analysis; the PLS-SEM analysis produces lower forecast errors for all indicators. For example, for the model estimation using PLS-SEMs, RMSE values of CPD1-CPD8 are 0.661, 0.384, 0.514, 0.396, 0.397, 0.456, 0.462 and 0.510 respectively, whereas, for these indicators, LM produces RMSE values of $0.691,0.388,0.519$, $0.398,0.399,0.469,0.466$ and 0.511 respectively. The negative figures in table 10 indicate the model has a high predictive power since all the PLS-SEM indicators are less than the naïve LM-RMSE values. 


\section{Discussion}

The study aimed to evaluate the impact of traditional communication channels on customer buying decisions. The findings disclosed that television advertisements have a significant positive influence on customer purchase decisions. It is comparable to some past studies that found television advertisements an essential determinant of customer purchase decisions (Anute et al.; Majeed \& Razzak, 2011; Mustafa \& AlAbdallah, 2020). With the above evidence, marketers need to pay more attention to television advertisement channels when promoting their products or services in Ghana because it has the most significant effect on customer purchase decisions, according to this study. The visuals and sounds of television help advertisers appeal to diverse senses simultaneously- if the visual doesn't attract you, the music may attract you in one way or the other. Therefore, television advertisement's content must be attractive, educative, interesting, and entertaining, thus influencing the customer purchasing decision. Marketers must see television advertisements as an opportunity to increase awareness of goods and services, thus increasing sales.

Also, the findings disclosed that outdoor advertisement has a significant positive influence on customer purchase decisions. More fantastic support was reported in several prior studies, which found outdoor advertisement critical in influencing customer purchase decision (Demiri \& Zekiri; Mustafa \& Al-Abdallah, 2020; Okanazu \& Madu, 2020; Sah, 2020; Warraich \& Ali, 2020). Organizations or advertisers must carefully choose an outdoor commercial's content as it plays a crucial role in persuading customers purchasing decisions. Advertisers should mount billboard designs that contain messages that are smart, short, clear, straightforward, pleasant, visible, and often visual to customers. This would impact the customer's purchase decision due to the easy access to outdoor commercials mounted by the roadside and the fact that outdoor advertisements are widely surrounding the consumers' environment all the time.

Moreover, this paper's results show that newspaper advertisement substantially impacts customer purchase decisions and is consistent with previous studies (Ingavale, 2013; Mustafa \& Al-Abdallah, 2020). This finding means that the newspaper advertisement is a critical factor that affects customer's purchase decisions. Therefore, this result's practical implication suggests that marketers or organizations use newspapers in promoting products or services, but the content of the commercial in newspapers must be informative.

The findings disclosed that radio advertisement significantly and positively impacts customer purchase decision. This finding is similar to previous researchers' findings who also revealed that radio advertisement significantly affects customer purchase decisions (Ayimey et al., 2013; Efstathiou, 2020; Mustafa \& Al-Abdallah, 2020; SRIVASTAVA, 2017). The findings indicate that radio advertisement can be seen as a fundamental indicator of customer purchase decisions. Therefore, marketers need to concentrate on radio advertisements in promoting goods and services because of their wide reach and affordability.

\section{Conclusion}

On the grounds of this study, advertisers need to count on television advertisements when promoting products and services; careful picking of the content of television advertisements as they perform a crucial role in affecting customer buying choices. Television advertisements should have a substantial share of any commercial budget. However, all communication networks should cooperate and function to produce the needed outcomes. This study revealed that advertisements that customers can see with their eyes have a greater effect on their buying decision; because both television and outdoor commercials significantly impact consumers' purchasing decisions.

\section{Limitation and Future Direction}

The research did not involve people outside Ghana. Future research may also be performed to address the limitations described by expanding the research to other settings and countries to achieve an extensive 
generalization of the analysis. It will be a fascinating area to perform research that focuses on television as a contact medium independently to determine why it has the greatest impact on consumers' buying decisions.

Funding: This research received no external funding.

Acknowledgments: We acknowledge there was no external funding support; all authors contributed accordingly in every part of the paper.

Conflicts of Interest: The authors declare no conflict of interest.

\section{References}

Afzal, S., \& Khan, J. R. (2015). Impact of online and conventional advertisement on consumer buying behaviour of branded garments. Asian Journal of Management Sciences \& Education, 4(1), 125-135.

Ahakwa, I., Yang, J., Tackie, E. A., Odai, L. A., \& Dartey, S. (2021). The Effects of Job Autonomy, Organizational Learning, and Work Environment on Organizational Commitment of Public Sector Employees in the Ashanti Region of Ghana.

Alalwan, A. A. (2018). Investigating the impact of social media advertising features on customer purchase intention. International Journal of Information Management, 42, 65-77.

Anu, M., \& Aswathy, S. (2014). Influence of television advertising and purchase decision making of FMCG-A study Hindustan Unilever Limited. IRACST-International Journal of Commerce, Business and Management, 3(5), 744-747.

Anute, N., Deshmukh, A., \& Pawar, S. Effects of Television Advertising Elements on Customer's Purchase Decision and Brand Building.

Ayimey, E. K., Awunyo-Vitor, D., \& Gadawusu, J. K. (2013). Does radio advertisement influence sale of herbal products in Ghana? Evidence from Ho Municipality.

Chin, W. W., Peterson, R. A., \& Brown, S. P. (2008). Structural equation modeling in marketing: Some practical reminders. Journal of Marketing theory and Practice, 16(4), 287-298.

Cohen, S. (1988). Perceived stress in a probability sample of the United States.

Costa, J. C. (2014). The impact of advertising on students: An empirical study of students from Goa. International Journal of Advanced Research in Management and Social Sciences, 3(12), 239-249.

Danaher, P. J., \& Rossiter, J. R. (2011). Comparing perceptions of marketing communication channels. European Journal of Marketing.

Demiri, B., \& Zekiri, J. The Impact Of Outdoor Advertising On Consumer Behavior _ A Thesis Presented To.

Domazet, I. S., Đokić, I., \& Milovanov, O. (2017). The Influence of advertising media on brand awareness. Management: Journal of Sustainable Business and Management Solutions in Emerging Economies, 23(1), 13-22.

Efstathiou, N. (2020). Assessing the influence of radio advertising on consumer purchasing decisions. North-West University (South Africa).

Fornell, C., \& Larcker, D. F. (1981). Evaluating structural equation models with unobservable variables and measurement error. Journal of marketing research, 18(1), 39-50.

Gijsenberg, M. J., \& Nijs, V. R. (2019). Advertising spending patterns and competitor impact. International Journal of Research in Marketing, 36(2), 232-250.

Hair Jr, J. F., Hult, G. T. M., Ringle, C., \& Sarstedt, M. (2016). A primer on partial least squares structural equation modeling (PLS-SEM): Sage publications.

Halldorsson, B., Castelijn, S., \& Creswell, C. (2019). Are children with social anxiety disorder more likely than children with other anxiety disorders to anticipate poor social performance and reflect negatively on their performance? Journal of Affective Disorders, 245, 561-568. doi:https://doi.org/10.1016/i.jad.2018.11.021

Henseler, J., Ringle, C. M., \& Sarstedt, M. (2015). A new criterion for assessing discriminant validity in variance-based structural equation modeling. Journal of the academy of marketing science, 43(1), 115-135.

Herget, A.-K., Schramm, H., \& Breves, P. (2018). Development and testing of an instrument to determine Musical Fit in audio-visual advertising. Musicae Scientiae, 22(3), 362-376.

Idris, I., Suhana, S., Ahmad, A., \& Wong, C. M. K. (2020). The impacts of social media advertisements on millennial's consumption. TEST Engineering and Management, 82, 5537-5544.

Ingavale, D. (2013). An impact of advertisements on purchase decision of youth with reference to consumer goods. Advances in management, 3(1), 18-22. 
Kim, J. H. (2019). Multicollinearity and misleading statistical results. Korean journal of anesthesiology, 72(6), 558.

Kline, R. B. (2011). Convergence of structural equation modeling and multilevel modeling: na.

Kumar, D. P., \& Raju, K. V. (2013). The role of advertising in consumer decision making. IOSR Journal of Business and Management, 14(4), 37-45.

Lankford, A. (2018). Do the media unintentionally make mass killers into celebrities? An assessment of free advertising and earned media value. Celebrity Studies, 9(3), 340-354.

Lee, E.-B., Lee, S.-G., \& Yang, C.-G. (2017). The influences of advertisement attitude and brand attitude on purchase intention of smartphone advertising. Industrial Management \& Data Systems.

Mahalaxmi, K., \& Ranjith, P. (2016). A Study on Impact of Digital Marketing in Customer Purchase Decision in Trichy. International Journal for Innovative Research in Science \& Technology, 2(10), 332-338.

Majeed, S., \& Razzak, S. (2011). The impact of television advertisement repetition, celebrity endorsement and perceived quality on consumer purchase decision. Australian journal of basic and applied sciences, 5(12), 3044-3051.

Malthouse, E. C., \& Calder, B. J. (2018). From advertising to engagement. The Handbook of Communication Engagement, no, 411-420.

Mehdi, Q., Paris, C. M., \& Balasubramanian, S. (2019). Exploring the role of Humor and Music in radio advertisement: A quasi-experimental study on domestic tourist attitudes and behavioral intentions in the UAE.

Modikeng, M. (2018). The influence of radio and newspaper advertisements on the buying decisions of consumers. Interim: Interdisciplinary Journal, 17(1), 1-17.

Mogaji, E., Czarnecka, B., \& Danbury, A. (2018). Emotional appeals in UK business-to-business financial services advertisements. International Journal of Bank Marketing.

Mustafa, S., \& Al-Abdallah, G. (2020). The evaluation of traditional communication channels and its impact on purchase decision. Management Science Letters, 10(7), 1521-1532.

Okanazu, O. O., \& Madu, M. A. (2020). Position Of Advertising In Strengthening The Purchase Decision Of 21st Century Business Education Students On Cosmetic Products. Nigerian Journal Of Business Education (Nigjbed), 7(2), 336-349.

Osewe, G. O. (2013). The effectiveness of internet advertising on consumer behaviour: The case of University of Nairobi students. University of Nairobi.

Oviedo-Trespalacios, O., Truelove, V., Watson, B., \& Hinton, J. A. (2019). The impact of road advertising signs on driver behaviour and implications for road safety: A critical systematic review. Transportation research part A: policy and practice, 122, 85-98.

Page, B., Anesbury, Z., Moshakis, S., \& Grasby, A. (2018). Measuring Audience Reach Of Outdoor Advertisements: Using Bluetooth Technology To Validate Measurement. Journal of Advertising Research, 58(4), 456-463.

Pourhossein, F., \& Mahmoudabadi, A. Original Paper Smart Urban Street Advertising Pattern Using Internet of Things Based on Environmental and Traffic Conditions.

Richards, J. I., \& Curran, C. M. (2002). Oracles on "advertising": Searching for a definition. Journal of Advertising, $31(2)$, 63-77.

Russo, V., Valesi, R., Gallo, A., Laureanti, R., \& Zito, M. (2020). "The Theater of the Mind”: The Effect of Radio Exposure on TV Advertising. Social Sciences, 9(7), 123.

Sah, S. K. (2020). Impact Of Advertising On Consumer Purchase Decision.

Saleh, H. (2017). Implementation Of The Green Advertising Media (Gam) To Increase Product Sales Volume (Psv) In Malaysia Product Market. Economic and Social Development: Book of Proceedings, 34-40.

Shafiq, A., Haque, A., Abdullah, K., \& Jan, M. (2017). Beliefs about Islamic advertising: an exploratory study in Malaysia. Journal of Islamic Marketing.

Shaikh, N. I., Hada, M., \& Shrestha, N. (2019). Allocating Spending On Digital-Video Advertising: A Longitudinal Analysis Across Digital and Television. Journal of Advertising Research, 59(1), 14-26.

Shmueli, G., Sarstedt, M., Hair, J. F., Cheah, J.-H., Ting, H., Vaithilingam, S., \& Ringle, C. M. (2019). Predictive model assessment in PLS-SEM: guidelines for using PLSpredict. European Journal of Marketing.

SRIVASTAVA, D. N. (2017). Advertisement influence and purchase decision of the consumers in India. International Research Journal of Engineering and Technology, 4(5), 2395-0056.

Tamilselvan, K., \& Kumaresan, S. Effectiveness Of Advertising On Consumr Buying Decision Making Style With Special Reference To Home Appliances At Chennai City.

Tao, J. (2020). The Influence of Message and Audio Modalities in Augmented Reality Mobile Advertisements on Consumers' Purchase Intention. San Jose State University. 
Tarik, Z., \& Adnan, S. (2018). Online vs Traditional; Marketing Challenge in the Telecom Market in Bosnia and Herzegovina. Economic Review: Journal of Economics and Business, 16(1), 45-57.

Warraich, H. A., \& Ali, T. (2020). The impact of advertising and promotion on purchase decision, sales and profitability of FMCG's (personal care) sector of Pakistan: Case study of Gillette Limited Pakistan and Treet Corporation limited Pakistan. Journal of Engineering and Economic Development, 6(1), 1-22.

Wielhouwer, P. W. (2020). Resistance and Response: Latinos and Conservative Radio Advertisements 1. Social Science Quarterly, 101(4), 1513-1533.

Zaglago, B. (2019). The Adoption Of Digital Marketing Among Smes In Ghana. 